\title{
TimeBanking: Towards a co-produced solution for power and money issues in inclusive research
}

\author{
Melanie Nind*a, Alan Armstrong ${ }^{\mathrm{b}}$, Mal Cansdale ${ }^{\mathrm{b}}$, Anne Collis ${ }^{\mathrm{b}}$, Clare Hooper ${ }^{\mathrm{c}}$, Sarah \\ Parsons $^{\mathrm{a}}$ and Andrew Power ${ }^{\mathrm{d}}$
}

*corresponding author,

Southampton Education School, University of Southampton, Highfield, Southampton, UK

Email: M.A.Nind@ soton.ac.uk Tel: 02380595813 Fax: 02380593556

\author{
${ }^{a}$ Southampton Education School, University of Southampton, Highfield, Southampton, UK \\ ${ }^{\boldsymbol{b}}$ Barod, Bangor Gwynedd, UK \\ 'IT Innovation Centre, Southampton, UK \\ ${ }^{d}$ Geography \& Environment, University of Southampton, Highfield, Southampton, UK
}

\begin{abstract}
This paper explores the potential of an online TimeBank for inclusive research to address some of the challenges related to the unequal distribution of power and money for researchers within and outside the academy working in collaboration. The problem, the concept of TimeBanking, and the relationship of TimeBanking to inclusive research principles are explained. The case is made for developing an online TimeBank for inclusive research, and an account is given of initial co-production of a prototype by an English interdisciplinary academic team and a Welsh workers cooperative set up and run by people with and without learning disabilities aiming to make public life more inclusive. The paper concludes that, while the concept is some way from becoming a reality, a hybrid digital-physical TimeBank, if accessible and flexible enough to attract usage, has potential for supporting democratised, inclusive research in practice.
\end{abstract}

Keywords: TimeBanking, inclusive research, co-production, democratisation, reciprocity 


\section{Introduction: Background to inclusive research and the potential for an online}

\section{TimeBank}

This paper explores some of the inherent challenges in inclusive research and how a TimeBanking approach might be used to address them. We are a partnership of academics and Community Interest Company (CIC) working with innovators in technology on the idea that TimeBanks could help us and others in doing research inclusively. We begin with defining the concepts and problems and providing some context. Inclusive research is an inherently eclectic and epistemologically diverse umbrella term for a 'whole family of approaches, all of which reflect a particular turn towards democratization of the research process' (Nind, 2014, p. 1). This democratization is about disrupting the traditional power dynamics in research - a response to the divide between academia (often portrayed as the 'ivory tower') and 'outside life' which, Kitchin and Hubbard (1999, p.196) argue, has maintained academia's supposed 'authority' and simultaneously undermined the ability of many marginalised people to contribute to the research process. It reflects a desire to do things right, and in solidarity with ordinary people, particularly those who are oppressed and victimized (Blomley, 2006).

Much of the work on inclusive research, including our own, has been done in the (learning) disability arena where challenges to the academy have been particularly felt. Under the umbrella of inclusive research, Walmsley and Johnson (2003) include participatory and emancipatory research, arguing that inclusive research is that which 'involves people who may otherwise be seen as subjects for the research as instigators of ideas, research designers, interviewers, data analysts, authors, disseminators and users' (p. 10). Latterly, building on categorisation of inclusive research by Walmsley and Johnson, Bigby, Frawley and

Ramcharan (2014) conceptualise types of inclusive research with disabled people: (i) leading and controlling the research, (ii) collaborating as researchers with academic partners, or (iii) acting in a steering or advisory capacity.

Inclusive research with people with learning disabilities has gained momentum over the last couple of decades. In the UK for example, public funding of the Learning Disability Research Initiative (Grant \& Ramcharan, 2007) stemmed from an explicit vision for people with learning disabilities as active citizens enjoying rights, independence, choice and inclusion (DoH, 2001). In Australia, 'inclusion in research of people with disability, their families and representative organizations' has been 'embedded as a principle in Australia's first national 
disability research agenda (Disability Policy \& Research Working Group, 2011)' (Bigby et al., 2014, p. 3). Across other research areas and in different disciplines, researchers are increasingly blurring the activist-academic interface, including working with climate justice networks, domestic violence NGOs and unemployed people (Wynne-Jones, North and Routledge, 2015), older people, children, people using health services or rejecting mental health services and so on (Nind, 2014). While these examples of inclusive research might involve as active researchers different kinds of marginalised groups, our focus is on research with people with learning disabilities in particular.

Inclusive research in the learning disability arena has the following characteristics: disabled people own the research problem, the research should be in their interests, they are involved in the conduct of the research, they control the research to some extent, and the research is accessible to them (Walmsely \& Johnson, 2003). Inclusive researchers often seek to make transparent the various roles of the different contributors to the research in order to make the case for credibility, head off accusations of tokenism, and help other inclusive researchers. This transparency in reporting also encourages reflection over potential tensions of trust, friendship, loyalty, guilt and discomfort as complicating ingredients in the mix of many authors' experiences (Wynne-Jones et al., 2015). It also exposes problem areas, such as unequal training for the different researchers and how this connects to who has skills and knowledge-based power (Nind, Chapman, Seale \& Tilley, 2015). Reflexive methodological accounts relate to the stages of the research process, particularly the goal that the people implicated by the research should be involved at all stages (Northway et al., 2014). The realities of compromise and the maturing into new stances on this goal reflect inclusive researchers working 'in a very principled way and in a realistic way' (Nind \& Vinha, 2012, p. 28). Ultimately, accounts of the research process show that much of how inclusive research ideals are borne out comes down to questions of power and money (including the cost of time) as we now explain.

\section{The power, time and money problem}

Next, we outline the complex issues of power, time and money in inclusive research that we have been trying to address. Each of us involved in this paper has been involved with inclusive research. Our contributions have been through working in partnerships, steering inclusive research, supporting it, conducting it, and seeking better understanding of it (e.g. Nind \& Vinha, 2012, Parsons \& Cobb, 2014; Power and Bartlett, in press). This experience, 
together with our review of the literature, has given us insight into the challenges inherent in working in this way, specifically challenges around the issues of power and money. In a study involving approximately sixty researchers with and without learning disabilities reflecting on their inclusive research practices, Nind and Vinha (2012) found that prickly power issues remained live for people; aspects like who could speak when and who could initiate research ideas were still monitored carefully, even when strong partnerships and, sometimes, friendships had formed.

Power and money are critical whatever model of inclusive research is adopted. When disabled people lead and control the research, power is the main issue and must, on principle, remain with disabled people. This means that if academic partners are involved, their power (assumed, inherent, invoked) has to be challenged at every step. In collaborative models, which can take many forms, it is often the case that power is (continuously) negotiated. Some people may be limited to occupying support roles unless interdependence and trust are sufficiently established (Nind \& Vinha, 2012). Where people are uncomfortable with taking a lead role, opportunities for participation may reflect individual levels of readiness for involvement (Seale, Nind \& Parsons, 2014). Collaboration often necessitates funding for unsalaried partners (usually from outside universities) to be fully involved, which can be problematic (see discussion below). Advisory or steering models still require that advisory group members and researchers wrestle with power in the process of working out the dynamic between them (Porter, Parsons \& Robertson, 2006).

A good example of the power and money challenges comes from The Learning Disabilities Research Team (LDRT, 2006) report on their study of the workings and outcomes of the thirteen projects in the UK government’s $£ 2$ million Learning Disability Research Initiative in which researchers were asked by the Department of Health funding them to embrace inclusive principles. While people with learning disabilities in the LDRT study were leading and controlling, this was not the case in the other projects they looked at. The LDRT observe that, "Very few people with learning difficulties are paid as researchers but what makes good involvement work is the right people, the right money, the right planning and time, and imagination' (p.14). The team were fully grant-funded, but even so a support organization needed to lend them money for meeting expenses until the contract was agreed with the Department of Health, illustrating the challenge for researchers working outside the supporting structures academy or commercial organization. Importantly for this research, 
they describe at length some of what was involved for them in working with a money currency and how this relates to power dynamics:

We eventually agreed the daily rate and how many days of work would be paid for. We also made the decision to pay ourselves and our supporters the same daily rate. This was very important for us. We believe that our supporters worked as colleagues and were part of the team, not silent people sat apart. Our philosophy is that we worked together in a team. We thought this should be reflected in the fee level ... We all had different circumstances in terms of our income and each person sorted out their money in a different way. Some of us wanted the money to go to our organisations, where it was added to our salary. Some of us were self-employed already. Others made agreements with our local Benefit Office to receive the money in equal monthly or weekly amounts at a rate that did not affect our benefits. (LDRT, 2006, p.46)

The LDRT concluded of the projects they studied that there was rarely 'real power-sharing happening' (p.81), linking this to problems with money and time. They noted how required resources have to be costed into applications for funding, but there is often not enough flexibility to respond to circumstances once a project gets going and funding is set. Moreover, disabled people, LDRT argue need to be involved before ideas and proposals are developed and before money is available to support this. We add that had the LDRT's own research been a collaboration with salaried academics, decisions about equal pay would have been more difficult to achieve in that the pay differential would have been larger. Our own research at the heart of this paper illustrates some of these challenges, even as we were working on developing a solution to them as we go on to describe.

\section{TimeBanks as a potential solution to inequality in payment and power}

To explore how TimeBanks might offer a potential solution to the challenges arising from inequality in payment and power in inclusive research we begin by defining the concept and explaining the principles, going on to discuss their development and the research evidence about their effects. TimeBanks are 'community-based mutual volunteering schemes whereby participants give and receive services in exchange for time credits' (Seyfang, 2004, p. 63, original emphasis), i.e. time becomes currency (Bretherton \& Pleace, 2014) with everyone's time being equal. TimeBanks can operate as a mechanism for the co-production of public 
services, as the time invested can come from professionals or other stakeholders or users of services (Glynos \& Speed, 2012). Early advocates of TimeBanks argued they could reduce social exclusion and generate social capital, in part because they create 'a fundamentally different relationship' between those involved in the exchange (Cahn in interview with Coff, 2011, p.18).

TimeBanking offers a potential solution to some of the challenges of inclusive research that we have discussed in this paper because the principles inherent to the TimeBanking movement fit with some of that which inclusive research is trying to do. These principles are explained by Edgar Cahn, founder of the movement in the USA in the 1980s,. First, TimeBanks are founded on the idea of people as assets and that 'Every human being can be a builder and contributor' (Cahn, 2004, p.24). Second, work itself is redefined in terms of 'taking back the power to define what we value' (p.124). Third, TimeBanking is about reciprocity: 'Wherever possible, we must replace one-way acts of largesse in whatever form with two-way transactions. "You need me," becomes "We need each other"” (p.24) Fourth, there is the core concept of social capital and that 'Social networks require ongoing investments of social capital generated by trust, reciprocity and civic engagement' (p.24).

In this conceptualisation of TimeBanks, we see echoes of the concern within inclusive research to include the people implicated in the research in its production (building and contributing to knowledge). Similarly, there is resonance in the idea that this collaboration should redress injustice in that inclusive research is about redressing the wrongs done when research has labelled, pathologized and colonised its subjects (Nind, 2014). The reciprocity principle is true of inclusive research in being fundamental to the idea of bringing into dialogue different ways of knowing for the benefit of all. Lastly, as with TimeBanks, the building of social networks and social capital is one of many jobs inclusive research is asked to do (Nind \& Vinha 2012).

In the UK, TimeBanking schemes have been running since 1998 (Burgess, 2014). While the early models are still permeating, new models are emerging, aided in part by the use of technology and by policy interest and support. New Labour and subsequent Coalition and Conservative Governments have been attracted by the potential of TimeBanks, in particular since the Localism Act 2011, seeking to decentralise (selected) services so they are led (where trusted) by active citizens, communities and the third sector. With such 'networks of mutual support' understood as important foundations to 'underpin healthy communities', 
Glynos and Speed (2012, p. 405) noted there were around 300 active or developing TimeBanks in the UK. Think Local Act Personal (nd), a national partnership motivated by seeing people who use social care services have a critical role to play in improving them, show the link between government agendas and community TimeBanking initiatives. More widely, Bretherton and Pleace (2014) observe that TimeBanking spans forty countries and six continents. They have flourished where traditional currency economies have struggled and where there are problems that can be solved by involving communities (such as among people who are homeless, unemployed, or marginalised through experiencing poor mental health or through being older or younger). There have been TimeBanks in prisons, schools and doctors' surgeries with people exchanging, for example, literacy help, physical training, dog walking, lifts and art classes. However, we have found no published accounts of their use in research contexts across inclusive research in its various guises. Exploring the potential application of the TimeBank idea to inclusive research could also shed light on why the challenges therein have remained outside the creeping influence of this significant movement.

Viewing everyone equally as valuable assets gives TimeBanks their equalising force. In TimeBanks, everyone has something to exchange which negates the idea of some people being more valuable and therefore more powerful, than any other. This parity of status fits well with the aspirations of inclusive research, where a "regime of recognition" (Glynos and Speed, 2012, p. 407) would sit equally well. The way that TimeBanks operate turn this parity principle into reality in that 'Everyone's time is equal, irrespective of what they choose to exchange' (Burgess, 2014, p. 3). This is attractive to inclusive researchers like ourselves who may want to eradicate the power differentials that trading in money brings, and who want to address the very real problems of lack of money for unsalaried parties to be involved in research ahead of attracting grant funding. Moreover, the use of time as currency in TimeBanks can operate on a number of levels: person-to-person, person-to-agency, or agency-to-agency (Gregory, 2013).

An extensive literature demonstrates the aspirations for TimeBanks in terms of the impact they are hoped to make. These desired impacts, Naughton-Doe (2014) suggests are at the level of the individual, the community, institutions and society. While the latter three centre on the benefits of co-production and cost savings, individual benefits relate to wellbeing/mental health, physical health, social capital, social inclusion, reduced social isolation/social exclusion, and increased employability/ employment. Achieving such impacts 
rests in part on the premise that 'Time Banks strive to make people feel useful and in doing so may have the capability to transform lives' (Bretherton \& Pleace, 2014, p. 7). This transformative agenda echoes through inclusive research. Timebanking UK divide the impacts into economic, social justice, and building community. Hoped-for community impacts are about community regeneration and community cohesion, following Cahn's (2004, p. 14) argument that unlike commercial transactions, that 'leave us as strangers', in TimeBanking '[w]e may start as strangers, but we end in a social network that feels like neighbours who know each other and like extended family whose members can count on each other'. Inclusive researchers already report this feeling connected to some extent (Nind \& Vinha, 2012).

Some of the hoped-for impacts of TimeBanks have been shown to translate into reality. Collum et al. (2012) conducted a national survey of 96 TimeBanking coordinators, plus three case studies in the USA. In-depth case studies have also been conducted in the UK (e.g. Seyfang, 2004) and there have been various evaluations (Bretherton \& Pleace, 2014; Burgess, 2014; Letcher \& Perlow, 2009). Seyfang and Smith (2002) found TimeBanks to be effective in attracting the participation of socially excluded groups motivated by wanting to help other people, to make friends and meet people. Bretherton and Pleace (2014: 5) found that for individuals, TimeBank work has provided personal rewards, structured activity, self-respect and dignity. The routes provided into employment and accredited education were particularly valued and we see links here with the desire among people new to researcher roles doing inclusive research for a real, paid job.

The quality of evidence about what TimeBanks achieve varies. Glynos and Speed (2014, p. 406) comment on 'a growing literature that presents considerable qualitative and quantitative data to support widespread anecdotal reports that time banking has positive physical and mental health impacts upon members of such networks'. They refer to TimeBanks reaching out to socially excluded people and helping to integrate them within networks. However, despite evaluation evidence and many good news stories, a decade ago Seyfang (2004, p. 63) argued that TimeBanks 'are not well researched'. More recently, Bretherton and Pleace (2014, p. 7) note that there remains 'a lack of detailed empirical research exploring the potential benefits of Time Banking'. Our project to look at the potential of TimeBanking within inclusive research remains, by implication therefore, an exploratory endeavour. 


\section{Co-producing a prototype TimeBank: Research activity}

\section{Stage 1. Checking the validity of the idea}

Our intention from the start of this project was to co-produce a prototype TimeBank. In our early literature review work to check the validity of the idea (reported on above) we found the weight of argument and evidence sufficient to indicate that TimeBanking has potential as a means of supporting democratic engagement in research involving communities of people from inside and outside academic institutions. We were drawn by the idea that this could: a) facilitate matching people who need skills and knowledge with those who can offer them; b) address the problems associated with payment by facilitating a web of give and take of services rather than money; and c) address the wider challenge of democratising the research relationship and facilitating co-production. We also found however apposite research evidence about the challenges in making TimeBanks work and recognised that our efforts to develop TimeBanking for inclusive research would need to be informed by, and ultimately address these challenges.

Investigating other TimeBanks indicated that a TimeBank may require features that are less desirable within many models of inclusive research. For example, Naughton-Doe (2014), echoed by Burgess (2014), argues that the evidence indicates the importance of a time broker who understands and facilitates the concept. In inclusive research any such coordination role would also come with contentious real and perceived power. Seyfang and Smith (2002) found that a strong local presence helped build group cohesiveness and stimulate exchanges which enabled the working of TimeBanks. Inclusive research networks have been effective locally, where exchanges may happen informally (Nind, 2014), but we were interested in something that would work beyond the local and informal, hence our focus was on an online TimeBank. Moreover, the setting up of TimeBanks has been found to be time intensive (Burgess 2014) and their maintenance require ongoing support (Bretherton \& Pleace 2014). This could add to, rather than facilitate, the work of inclusive researchers. A first step for us, therefore, needed to be doing some research about the idea with other inclusive researchers to see how they perceived the potential affordances of a TimeBank for inclusive research.

\section{Stage 2: From validity checking to development of a prototype TimeBank}

Some of the principles surrounding TimeBanks and inclusive research coalesce around the concept of co-production. TBUK (p.12) argue in relation to co-production of services that a 
co-production approach means 'saying that the solution is found in the problem. By mobilising the hidden people power and resource that exists in all of us, we send a different signal: "people can"". They position co-production as the philosophy and TimeBanking as the mechanism. Co-production encapsulates the concept that provider and user can work actively together in the delivery of a service (Glynos \& Speed, 2012) or that researcher and research participant can share in the design and conduct of the research and production of knowledge.

We were already a partnership working across the academic divide. Barod, the Community Interest Company[Community group anonymised], had the initial idea that TimeBanks could help inclusive research. Melanie, an academic who was already exchanging skills, opportunities, ideas and money with the group, spotted the opportunity to fund some research into this from a Web Science stimulus fund scheme at the university. A team was put together to develop the proposal, though the academics led and were the only ones salaried at this point. Barod's [Community group] time for the project was costed at their common hourly rate as worker-directors. The academics' time was costed at various higher rates, but with much additional time not covered by the study budget though still salaried. A software developer was funded on a different daily rate again. On winning funding, the PRICE (Participation and Responsible Innovation in Co-Design for Exchange)[name anonymised] project came into being. We made decisions collaboratively throughout, though Melanie chaired the meetings and held responsibility for the grant. At the time of writing the paper, funding has ended and the academics are still salaried but Barod[community group] has no funding for their time. We are trying to balance this out in a system of bartering our time using reciprocal exchange principles from TimeBanking.

To try to create a TimeBank solution to some of the challenges of inclusive research it would have been incongruous with our principles around engaging with the users of research, to attempt this without working to include potential users (beyond ourselves) in thinking about the design issues.. By working in partnership with users from the start of the project our work aligned with the principles of participatory design, in particular Druin's (2002) conceptualisation of design partners in technology design and development. In line with the principles of shared power within inclusive research, the role of design partner is one that aims to embed more equal power relationships within the design relationship. Our work progressed through a series of activities to design and develop a working prototype and we discuss these activities next. 


\section{Focus group}

We first conducted a focus group to explore how inclusive researchers would respond to the idea of a TimeBank for inclusive research and to join in the thinking around it. Focus groups offer spaces for 'deliberative, dialogic and democratic practice' (Kamberelis \& Dimitriadis, 2005, p.887), where complexities can be explored in non-hierarchical ways (Bagnoli \& Clark, 2010). We were particularly concerned with whether people engaged in inclusive research projects could see the potential of a TimeBank for inclusive research and if so, the potential to meet which needs and how. We approached an opportunistic sample from our networks in inclusive research and, using snowballing (Morgan, 2008), recruited clusters of two or three academics and disabled researchers who were familiar with working cooperatively and supportively with each other. The focus group comprised eight academic researchers and seven researchers with learning disabilities or, as a result of the snowballing recruitment, autism. Information leaflets and consent forms, given in advance, explained the research in simple, easy to read text supported by visual symbols. A similarly styled agenda clarified what the focus group would involve.

The focus group, which lasted two hours, was structured to include an introduction and icebreaker, followed by a workshop activity, small discussions, and plenary. The workshop part involved participants in identifying their 'needs' when conducting inclusive research and also considering what they could offer to others. By writing these things on cards, flagging where needs and offers connected, and literally connecting the people with a ball of wool, everyone was able to see a low tech model of a TimeBank for inclusive research emerge. Having teased out what we learned from the activity, focus group discussion followed the questioning route of how the low-tech version of the TimeBank could translate to a Web-based version. We flagged questions of accessibility, communication, and security and trust with respect to brokering needs and offers online. We recorded ideas from the free-flowing conversation on paper and posted these on the walls for easy reference. We also audio-recorded the discussion and combined written and audio data in later analysis.

\section{Twitter discussion}

To engage a wider community of participants in the developmental thinking, we conducted a second two-hour focus group online, via Twitter. Such an approach can be highly effective for democratising the engagement, discussion and generation of new ideas (Hooper, Nind, 
Parsons, Power \& Collis, 2015). We promoted the online discussion among people in our various networks with an interest in issues of power, participation, user experience and accessible design to participate in informing the development of the prototype TimeBank. The process of informed consent involved tweeting prior to and during the group with a link to the study webpage describing the study and how the data would be used. We specified that inclusion of the study hashtag (\#pricestudy) with a tweet denoted consent for us to use the content of that tweet as research data. The questioning route was similar to that used in the other focus group, with the anchor questions of (i) What would participants give and take from a TimeBank? (ii) Would they have worries about trust, accessibility, and communication? And (iii) What website functions would they want? There were 108 relevant contributions from 38 Twitter accounts. We used the Twitter Archiving Google Spreadsheet (TAGS) v.5.1 application to capture the data.

\section{Analysis}

Data about what might be exchanged on a TimeBank for inclusive research were analysed to generate a list that we mapped on to the stages of the research process, i.e. preparation, conduct, and sharing of research. We examined where needs and offers matched as an indicator of potential success for the operation of the TimeBank and listed separately any unreciprocated items which would require further consideration. The matching process highlighted the different ways participants communicated roughly the same thing (see the approximately matched rows in Table 1), but the question arose of how the need for this kind of interpretation of people's intended communication could be circumvented in an online TimeBank operating without a broker. Data on accessibility, communication and security, which concerns how the TimeBank would be used rather than what it would be used for, were thematically analysed by hand by two of the academics and shared with the wider group. Analysis of the 240 tweets from the online focus group additionally involved removing material that was not relevant before coding the material thematically, first at the broad level of the three specific questions asked of the group and then in more detail.

\section{Themes from the data}

The first focus group participants identified more things they could offer to a TimeBank compared to the things that they could receive, as shown in Table 1 (recurrences are specified, otherwise things were mentioned once). This imbalance may reflect the greater 
ease of earning time credits than spending them reported by Bretherton and Pleace (2014).

Greater numbers of items classified as about planning and preparation of research than other stages could be due to an inclination to start one's thinking at the beginning of the process.

\begin{tabular}{|c|c|}
\hline Needs & Offers \\
\hline \multicolumn{2}{|c|}{ Planning \& preparation } \\
\hline $\begin{array}{l}\text { Bid \& proposal writing } \\
\text { Help getting longer \& larger bids } \\
\text { Fundraising }\end{array}$ & $\begin{array}{l}\text { Support to turn people's ideas into research } \\
\text { Writing bids } \\
\text { Support with form filling } \\
\text { Budget planning }\end{array}$ \\
\hline $\begin{array}{l}\text { Link to real world/lived experience outside } \\
\text { academy } \\
\text { Connect with organization that can use my } \\
\text { work }\end{array}$ & $\begin{array}{l}\text { Pooling ideas and matching people } \\
\text { Facilitation skills }\end{array}$ \\
\hline $\begin{array}{l}\text { Partners from other sites } \\
\text { Someone with shared interests } \\
\text { Commitment to support research for a } \\
\text { defined amount of time }\end{array}$ & $\begin{array}{l}\text { Researchers with a broad range of skills } \\
\text { Be a participant }\end{array}$ \\
\hline Access to social science expertise & Cross-disciplinary knowledge \\
\hline $\begin{array}{l}\text { Input regarding usefulness \& relevance of } \\
\text { research (occurring twice) }\end{array}$ & $\begin{array}{l}\text { CPF group with knowledge \& experience to } \\
\text { share }\end{array}$ \\
\hline $\begin{array}{l}\text { Advisory group members } \\
\text { Bidding partners/database of interests }\end{array}$ & $\begin{array}{l}\text { [Our People First organization] have } \\
\text { contacts! }\end{array}$ \\
\hline Support with ethics \& ethics committees & Ethics advice \\
\hline \multicolumn{2}{|c|}{ Conducting research } \\
\hline $\begin{array}{l}\text { Help making research information or } \\
\text { consent forms accessible (occurring } 4 \text { times) }\end{array}$ & $\begin{array}{l}\text { Notetaking into easyread } \\
\text { Easyread (occurring } 4 \text { times) } \\
\text { Simplifying ideas }\end{array}$ \\
\hline $\begin{array}{l}\text { Applying for next project while still } \\
\text { working on this one }\end{array}$ & Managing a project \\
\hline $\begin{array}{l}\text { Help with data capturing forms/methods } \\
\text { Help talking to people }\end{array}$ & $\begin{array}{l}\text { Help with interviews } \\
\text { Research skills } \\
\text { Data collection } \\
\text { Training in doing research } \\
\text { Help with life story work }\end{array}$ \\
\hline $\begin{array}{l}\text { Support for group members around issues } \\
\text { that come up }\end{array}$ & $\begin{array}{l}\text { CPF have skills, talent and knowledge of } \\
\text { learning disability field } \\
\text { Knowledge of circles of support }\end{array}$ \\
\hline \multicolumn{2}{|l|}{ Transport } \\
\hline & Honorary research assistantship/fellowship \\
\hline & Help to pay self-advocates for research \\
\hline & Literature reviewing \\
\hline
\end{tabular}




\begin{tabular}{|c|c|}
\hline $\begin{array}{l}\text { Sharing research messages with people who } \\
\text { need to hear them } \\
\text { Examples of accessible dissemination } \\
\text { Marketing support }\end{array}$ & $\begin{array}{l}\text { Dissemination in writing \& presentations } \\
\text { Help with publishing findings } \\
\text { Publicity for projects } \\
\text { Writing research reports (occurring twice) } \\
\text { Writing blogs } \\
\text { Writing articles } \\
\text { Writing for online format } \\
\text { Showing people how to do accessible } \\
\text { research project } \\
\text { Workshop on communication } \\
\text { Art work }\end{array}$ \\
\hline Film-making (occurring twice) & $\begin{array}{l}\text { Film \& animation } \\
\text { [Our People First organization] media group } \\
\text { with skills \& equipment }\end{array}$ \\
\hline $\begin{array}{l}\text { Help with tweeting (occurring twice) } \\
\text { New technologies \& social media } \\
\text { (occurring twice) }\end{array}$ & $\begin{array}{l}\text { Lessons in twitter } \\
\text { Social media \& twitter (occurring twice) } \\
\text { CPF media group with skills \& equipment } \\
\text { Making technology accessible } \\
\text { Knowledge of virtual environments, } \\
\text { websites, apps, software } \\
\text { Using the computer }\end{array}$ \\
\hline & Nice conference venue \\
\hline \multicolumn{2}{|c|}{ A bit outside research itself } \\
\hline $\begin{array}{l}\text { Workshop about lived experience of people } \\
\text { with learning disabilities } \\
\text { Learning opportunities for students }\end{array}$ & $\begin{array}{l}\text { [Our People First organization] group with } \\
\text { knowledge \& experience to share }\end{array}$ \\
\hline Legal advice & $\begin{array}{l}\text { Making criminal justice system more } \\
\text { accessible }\end{array}$ \\
\hline \multicolumn{2}{|l|}{ Solutions for hearing problems } \\
\hline \multicolumn{2}{|l|}{ Resource to help overcome being silo-ed } \\
\hline \multicolumn{2}{|l|}{ Finding good support workers } \\
\hline \multicolumn{2}{|l|}{ Cake making! } \\
\hline & $\begin{array}{l}\text { Activities: Showing people around an area, } \\
\text { men's night at church }\end{array}$ \\
\hline & $\begin{array}{l}\text { Access: to theatres and galleries, to } \\
\text { university resources }\end{array}$ \\
\hline & $\begin{array}{l}\text { Experience: TimeBanks, Setting up as a } \\
\text { CIC }\end{array}$ \\
\hline & Skills: Teaching \\
\hline & $\begin{array}{l}\text { Knowledge: saving money \& energy, pets, } \\
\text { being a good mum/dad, local area, schools, } \\
\text { networks }\end{array}$ \\
\hline
\end{tabular}

Table 1. The things participants wanted to exchange showing potential matches and mismatches and the different ways of wording similar needs and offers 
Participants were enthusiastic about the potential of an online TimeBank, even within the small face-to-face group, for brokering useful exchanges within inclusive research, though the realities of making that happen were evident in the discussion data (see summary of concerns in Table 2). Participants in the Twitter discussion were less concerned about what users of the TimeBank might need or offer for exchange and more interested in the process of how the exchange would take place. Table 2 shows a synthesis of the concerns and potential solutions from both data gathering events.

\begin{tabular}{|c|c|}
\hline Concerns & Suggested mechanisms \\
\hline Fairness and reciprocity & $\begin{array}{l}\text { Providing clear parameters \& transparent } \\
\text { working } \\
\text { Good entry level information } \\
\text { Use of social media to build community } \\
\text { Aspects of gamification (e.g. star ratings) to } \\
\text { encourage active engagement }\end{array}$ \\
\hline $\begin{array}{l}\text { Access by people with different } \\
\text { communication needs }\end{array}$ & \multirow{2}{*}{$\begin{array}{l}\text { Assistive technology } \\
\text { Tablet \& smart phones } \\
\text { A developer 'hack day' to help build or } \\
\text { fine-tune the software } \\
\text { User-centred design } \\
\text { Specific website functions }\end{array}$} \\
\hline Access by people who may not read & \\
\hline $\begin{array}{l}\text { Involvement of peopl } \\
\text { technology/ digital ex }\end{array}$ & \\
\hline Trust and security & \multirow{3}{*}{$\begin{array}{l}\text { Code of practice } \\
\text { Short video clips with examples of } \\
\text { successful exchanges to help demonstrate } \\
\text { trustworthiness } \\
\text { Regional meet-ups }\end{array}$} \\
\hline Online safety & \\
\hline $\begin{array}{l}\text { Most online safety information about social } \\
\text { media says never to meet up with people } \\
\text { you have only met online }\end{array}$ & \\
\hline
\end{tabular}

Table 2: The concerns and potential mechanisms in how participants thought a TimeBank might work Development of the prototype

We drew on the analysis of these data to begin to work more closely with the software developer to build a prototype. This process began with each member of the core 'design partner' team writing individual specifications for the features and content that they felt should be included, and then jointly compiling these specifications into an overall design 'wish list'. Individual specifications provided step-by-step user 'walk throughs' in which we tried to envisage each webpage on the site. This was then discussed in-person with the developer and further refined. After initial design and some further small-scale refinements, the resulting prototype web application was developed for external review. The site featured 
an opening 'splash page' with links to describe the PRICE project, a defintion of the TimeBank, our 'rules', and guidelines on how to get the best from the TimeBank. The website was designed to allow users to register and log in. Then the TimeBank feature gave the option of generating a request for a 'need' or an 'offer' managed as hours in credit or debit.

\section{Post-development user feedback}

Once we developed the prototype for testing, we conducted focused discussions on its usability, accessibility and proof of concept. This stage comprised sharing the link with people so they could try out the software for themselves and communicating feedback faceto-face or online. Seven people participated: two inclusive researchers from the original faceto-face focus group; two experts in web accessibility; one academic doing collaborative work in health; and two people with learning disabilities (one familiar with TimeBanks but not using the Web and one familiar with the Web but not TimeBanks). Participants provided feedback on the mechanics of things like ease of logging in and navigating, accessibility of terms, level of safety people thought they would experience when using the TimeBank, additional features they would like, and their response to the whole concept. Once again, there was considerable enthusiasm for an online TimeBank for inclusive research and for university-public collaborative working more generally, though concern that the concept of the TimeBank may be hard to communicate. Participants were generous in sharing their expertise regarding possible solutions to some of the accessibility, usability and trust challenges.

\section{Discussion: Producing an online Timebank for inclusive research}

This discussion returns to the question of whether a TimeBank might help with some of the fundamental challenges in inclusive research, particularly surrounding time, money and power. One of the issues to emerge from the research was the role of human mediation in facilitating exchanges in a time rather than monetary economy. The importance of a proactive, enabling broker to foster networking was evident in the literature and a potential solution to the trust and safety challenges. A broker could interpret needs and offers to match them more sensitively than might be possible in an automated, online system. The prototype employed a dropdown list of choices to resolve the issue of moderation of free-text inputs to 
the system. This, however, presumes that inclusive research and the people involved in it are more predictable than might actually be the case. Yet, unless an online TimeBank for inclusive research manages without a human broker, we are back to the issue of who such a broker would be and what power they might inadvertently wield. There are dangers (again linked to fairness and reciprocity as well as power) inherent in gearing the TimeBank more toward academic rather than community needs and an academic broker/coordinator could exacerbate such unbalance. A solution might be rotating the broker role around the network of academic and community researchers.

In terms of democratizing research several issues emerged. One was the possible role of gamification within an online TimeBank for inclusive research; that is, 'the use of game design elements in non-game contexts' (Deterding, Dixon, Khaled, \& Nacke, 2011). Participants expressed an interest in developing this aspect in which TimeBankers might earn rewards or badges for playing the TimeBank 'game' well. The role this could play in recognising the things people do is not trivial. One participant likened this to the role of badging the contribution made by people who give blood. Another participant stressed the importance, within his problematic money economy, of adequately thanking people from outside the academy for their contributions to it, and showing how these make a difference. The danger, though, of focusing too much on this approach to marking contributions, such as 'gold user' badging in a TimeBank, is that the sense of reciprocity could be lost. Needing as well as giving has to be recognised if Cahn's TimeBanking principles are to be operationalised and the intrinsic mutuality of this has to be retained.

The difference in the number of offers compared with needs suggested by participants in the first focus group flags a potential problem in the working of a TimeBank for inclusive research. Our research comprised only a small group and a short exercise, but once again suggests that the principle of reciprocity - and the detail of reciprocity with whom - may be challenging to operationalise. While discussions about fairness included participants worrying about the possibility of people taking from, but not giving to, the TimeBank, the opposite may well be the more likely problem. This is where the level of gamification and debt and credit limits would need careful consideration and ongoing monitoring to have the desired effect on stimulating activity where it is needed.

The essential idea of a TimeBank for inclusive research is that it reflects the idea that inclusive research needs people who are inside and outside the academy, and inside and 
outside the phenomenon or group the research is about, to work together to co-produce knowledge. We conceived the TimeBank as being a vehicle for facilitating such combinations, allowing people who may not already have good networks to build them. If more people offer services than express needs, then it may be that what is needed is something other than a TimeBank. While the TimeBanking philosophy matches well with principles of inclusive research, it might be that the people doing inclusive research are doing so because they have already established working relationships across the divide of being within or outwith the academy. Had we invited self-advocates or academics with an interest in, rather than experience of, inclusive research, then it might have been that the needs they expressed outweighed the things that they felt they could offer for exchange. The implication of all this is that a TimeBank for inclusive research may need a particular balance of people working through it for the exchange dynamic to be effective. Too many experienced inclusive researchers, or too many people from inside or outside the academy could unbalance things so dramatically that productive exchanges could not happen.

The inside/outside dichotomy may sometimes be somewhat artificial when, as collaborations flourish, traditional roles are disrupted, but it is unlikely to become a redundant concept. The data indicate that participants were interested in people from outside (or inside) the academy exchanging with each other rather than just across the salaried-unsalaried divide. On discussing the data, we discovered that amongst the project team we had different views about whether we had anticipated this or seen it as one of the purposes or desired functions of the TimeBank. Similarly, some participants were keen to use such a TimeBank to make exchanges outside of the realm of research, arguing that self-advocate needs would be likely to extend into things like making sense of other paperwork and academic needs would include self-advocates contributing to teaching as well as to research. The question emerges of how a TimeBank might evolve: could it begin as a TimeBank for inclusive research and evolve into something else? Again, a broker or co-ordinator might be able to steer the extent of diversification of activity, but would the power to do this be a welcome or unwelcome aspect? Similarly, we have been exploring TimeBanking for inclusive research, but researchers more widely are concerned with the ethics of what is given and taken in the research process, particularly in the context of drives towards engagement with, and impact on, the people the research is designed to benefit. A broadening out of the usage of a TimeBank for inclusive research to other research and knowledge exchange is easily 
envisioned, subtly - or less subtly - altering the way that altruism and generalised reciprocity might feature for people participating in research.

\section{Next steps}

At the time of writing we have a basic prototype online TimeBank in the form of a piece of software with some of the required functionality to request and document exchanges of time. We have a number of inclusive researchers highly interested in the concept. The next steps include 1) technical development; 2) design development; 3) working out how the TimeBank might serve inclusive research in practice. Our collaborative research has provided a strong steer on the technical requirements for the next iteration of the software to make it accessible enough for further testing with users. These are discussed in a technical paper (Hooper et al., 2015) and are not the focus here. Further design and development work is necessary for the accessibility, utility and attractiveness of the software. Finally, study of how the TimeBank might serve inclusive research requires more of a participatory action research approach, engaging inclusive researchers in problem-solving as they generate and consider data about its use. It is only when the technical work has reached a certain stage that we will be able to know how people, including ourselves, will use the TimeBank. It is only when it is in use that we will begin to know whether the TimeBank can help alleviate the problems in inclusive research around money and power.

We plan to start with a small community and grow organically. The pace of growth will depend on funding and on whether the TimeBank serves a purpose (our intended purpose or otherwise) as well as on the practicalities of resolving problems as they arise. We will need to research how fairness, reciprocity, trust and security are negotiated and experienced, how connectedness and community are fostered, and how the rules need to adapt to changes in the size or cultural composition of the TimeBank users. Ultimately, there is considerable potential to scale up the TimeBank. It need not be limited to use amongst people with learning disabilities and their collaborators engaging in research, though developing it with this community in mind would be likely to ensure it accessibility for most other groups. Some of our research participants saw its potential for other purposes, particularly in the arena of patient and public involvement in health sciences in universities, where for one participant 'payment to patients/service users is the bane of my life'. Here again we see that the questions of what someone's time is worth/how they should be recompensed (for teaching a group, being on a reference group or supporting student recruitment) is problematic when 
universities and people receiving state benefits are involved. The opportunity to be more creative and to work in a different currency is attractive as a solution. The question might then become about what is distinctive about this TimeBank compared to any other and how might it establish its boundaries.

\section{Conclusion}

Researching the potential of an online TimeBank to support inclusive research has reinforced the potential of this idea for addressing some of the issues associated with power, time and money that collaboration between differently resourced and differently powered researchers can bring. We return to the helpful discussion by Bigby et al. (2014) of models of how inclusive research collaborations can work that we discussed in early part of this paper. They argue that inclusive research can meet the distinctive as well as shared agendas of collaborating partners, providing these purposes are attended to and valued similarly, and they could be within a TimeBank. A critical function of inclusive research is 'to generate new knowledge that neither group could do alone' (Bigby et al., 2014, p. 8). If (in the field of learning disability research in particular) the challenges associated with digital literacy can be addressed, then a TimeBank could have a role to play in exchanging the skills that an academic partner or a community partner (or partner working in the in-between zone) may lack. This can only help in the inclusive research agenda of doing research that is meaningful, impactful and valid for those implicated in it. We are, however, some way yet from the reality of making that happen. 


\section{Acknowledgements}

We gratefully acknowledge the contribution of our participants, accessibility advice from Sarah Lewthwaite and the software development of Ken Meacham.

This research was supported by University of Southampton Web Science Institute Research Collaboration Stimulus Funding. 


\section{References}

Bagnoli, A. \& Clark, A. (2010) Focus groups with young people: a participatory approach to research planning. Journal of Youth Studies, 13, 101-119.

Bigby C., Frawley, P. \& Ramcharan, P. (2014) Conceptualizing inclusive research with people with intellectual disability, British Journal of Learning Disabilities, 27, 3-12.

Blomley (2006) Uncritical critical geography? Progress in Human Geography, 30, 87-94.

Bretherton, J. \& Pleace, N. (2014) An evaluation of the Broadway Skills Exchange Time Bank. Centre for Housing Policy, University of York.

Burgess, G. (2014) Evaluation of the Cambridgeshire Timebanks. Cambridge: Cambridge Centre for Housing and Planning Research.

Cahn, E. (2004) (2 $2^{\text {nd }}$ edn) No more throw-away people: The co-production imperative. Washington, D.C: Essential Books.

Coff, R. interview with E. Cahn. 2011. Father time, New Start, 10 November 2011, 18.

Collom, E., Lasker, J., Kyriakou, C. (2012, August) Equal time, equal value: Building healthier communities through Time Banking. American Sociological Association Conference, Denver, Colorado,

Deterding, S., Dixon, D., Khaled, R., \& Nacke, L. (2011, September). From game design elements to gamefulness: defining gamification. In Proceedings of the 15th International Academic MindTrek Conference: Envisioning Future Media Environments (pp. 9-15). New York: ACM.

DoH (Department of Health) (2001) Valuing People: A new strategy for learning disability for the 21 st century. London, The Stationery Office.

Druin, A. (2002) The role of children in the design of new technology. Behaviour and Information Technology, 21, 1-25.

Grant, G. \& Ramcharan, P. (2007) Valuing People and research: The Learning Disability Research Initiative. Overview Report. DoH. 
Glynos, J. and Speed, E. (2012) Varieties of co-production in public services: time banks in a UK health policy context. Critical Policy Studies, 6, 402-433.

Gregory, L. (2013) Improving health through participation: time banks as a site for coproduction. $\mathrm{PhD}$ thesis, Cardiff University.

Hooper, C., Nind, M., Parsons, S.J., Power, A. \& Collis, A. (2015) Building a Social Machine: co-designing a TimeBank for inclusive research, WebSci '15, June 28 - July 01, 2015, Oxford, UK. DOI: http://dx.doi.org/10.1145/2786451.2786472

Kamberelis, G. \& Dimitriadis, G. (2005) Focus groups: Strategic articulations of pedagogy, politics and inquiry. In: Denzin NK and Lincoln YS (eds) The Sage handbook of qualitative research (pp. 887-907) ( $3^{\text {rd }} \mathrm{edn}$ ). Thousand Oaks, CA: Sage,

Kitchin, R. and Hubbard, P. (1999) Research, action and 'critical' geographies, Area, 31, 195198.

Letcher, A.S. \& Perlow, K.M. (2009) Community-based participatory research shows how a community initiative creates networks to improve well-being, American Journal of Preventive Medicine, 37,

Morgan, D.L. (2008). Focus groups. In L.M. Given (ed.) The Sage encyclopedia of qualitative research methods (pp. 816-817). Thousand Oaks, CA: Sage.

Naughton-Doe, R. (2014, July) Time banking: Where is the evidence? Paper presented at Social Policy Association Conference Social Policy Confronting Change: Resistance, Resilience and Radicalism, University of Sheffield, UK.

Nind, M. (2014) What is inclusive research? London: Bloomsbury.

Nind, M. and Vinha, H. (2012) Doing research inclusively, doing research well? Report of the study: Quality and capacity in inclusive research with people with learning disabilities. www.southampton.ac.uk/education/research/projects/quality_and_capacity_in_inclusive research_with_learning_disabilities.page 
Nind, M., Chapman, R., Seale, J. \& Tilley, L. (2015) The conundrum of training and capacity building for people with learning disabilities doing research, Journal of Applied Research in Intellectual Disabilities, doi: 0.1111/jar.12213.

Northway, R., Hurley, K., O’Connor, C., Thomas, H., Bale, S. \& Langley, E. (2014) Deciding what to research: an overview of a participatory workshop, British Journal of Learning Disabilities 42, 323-27.

Parsons, S. \& Cobb, S. (2014) Reflections on the role of the 'users': challenges in a multidisciplinary context of learner-centred design for children on the autism spectrum. International Journal of Research and Method in Education, 37, 421-441.

Porter J., Parsons, S., \& Robertson C. (2006) Time for review: Supporting the work of an advisory group. Journal of Research in Special Educational Needs, 6, 11-16.

Power, A. \& Barlett, R. (in press) Self-building safe havens in a post-service landscape: how adults with learning disabilities are reclaiming the welcoming communities agenda, Social \& Cultural Geography.

Seale, J., Nind, M. \& Parsons, S. 2014. Inclusive research in education: Contributions to method and debate. International Journal of Research and Method in Education, 37, 347356.

Seyfang, G. (2004) Time banks: rewarding community self-help in the inner city. Community Development Journal, 39, 62-71.

Seyfang, G., \& Smith, K. (2002). The time of our lives: Using time banking for neighbourhood renewal and community capacity building. London: NEF.

The Learning Disabilities Research Team (2006) Let me in - I'm a researcher. London: DoH.

DoH (nd) Think Local Act Personal http://www.thinklocalactpersonal.org.uk/Browse/Building-CommunityCapacity/About_BCC/What_is_social_capital/Impact-of-socialcapital/Timebanking/TimebankingUK/

Timebanking UK (2011) People Can. London, UK. http://www.timebanking.org/people-can/ 
Wynne-Jones, S. North, P. \& Routledge, P. (2015) Practising participatory geographies: potentials, problems and politics, Area, 47, 218-221. 